\title{
Modeling and Validation of a Flywheel Energy Storage Lab-Setup
}

\author{
Francisco Díaz-González, Student Member, IEEE, Andreas Sumper, Member, IEEE, \\ Oriol Gomis-Bellmunt, Member, IEEE, Roberto Villafafila-Robles, Member, IEEE
}

\begin{abstract}
This work deals with the modeling, control and experimental validation of a flywheel test bench which is part of IREC's lab-scale microgrid. The storage device has been designed as a proof of concept. It is based on a low-speed rotating disk mechanically coupled to a Permanent Magnet Synchronous Machine. The electrical power is exchanged with the external grid by means of a set of back-to-back power converters. These power electronics control the speed of the machine, and thus the active power absorbed or injected by the device, and also regulate the reactive power at the point of common coupling with the external grid. Vector control techniques are used for designing the converter controllers: a field oriented vector control algorithm is implemented for governing the servomotor while the instantaneous power theory-based algorithm is used to manage the active and reactive currents flowing from the grid side converter. The control implementation in the experimental setup has been carried out by means of programming Digital Signal Processors (DSP's). The modeling and control system design has been validated after executing several experiments.
\end{abstract}

Index Terms-Flywheel Energy Storage System, Permanent Magnet Synchronous Machine, DSP, experimental validation

\section{INTRODUCTION}

$\mathbf{F}$ LYWHEEL Energy Storage System (FESS) is an electromechanical system that stores energy in form of kinetic energy. Its operation principle is based on the rotating movement of a disk. Nowadays, flywheel devices are hi-tech systems that involve the use of magnetic bearings in order to decrease friction at high speed, high efficient electrical motors, vacuum systems and advanced composite materials in order to optimize their design and performance [1], [2], [3]. Energy is transferred to the flywheel when the machine operates as a motor (the flywheel accelerates), charging the energy storage device. FESS is discharged when the electric machine regenerates through the drive (slowing the flywheel). The power capacity is limited by the rated currents of the

F. Díaz-González is with Catalonia Institute for Energy Research (IREC), C. Jardins de les Dones de Negre, 1, Pl. 2a, 08930 Sant Adrià del Besòs, Spain (e-mail: fdiazg@irec.cat).

A. Sumper is with Catalonia Institute for Energy Research (IREC) and also with Centre d'Innovació Tecnològica en Convertidors Estàtics i Accionaments (CITCEA-UPC), Departament d'Enginyeria Elèctrica, Universitat Politècnica de Catalunya EU d'Enginyeria Tècnica Industrial de Barcelona, C. Comte d'Urgell, 187, Pl. 2, 08036 Barcelona, Spain (e-mail: sumper@ citcea.upc.edu).

O. Gomis-Bellmunt is with Catalonia Institute for Energy Research (IREC) and also with Centre d'Innovació Tecnològica en Convertidors Estàtics Accionaments (CITCEA-UPC), (e-mail: gomis@citcea.upc.edu).

R. Villafafila-Robles is with Centre d'Innovació Tecnològica en Convertidors Estàtics i Accionaments (CITCEA-UPC), (e-mail: roberto.villafafila@citcea.upc.edu). servomotor and the power electronics of the system. The energy capacity of the system depends on the square value of its rotating speed $\omega_{m}$, and its inertia $J$ [4].

Flywheel devices can be used in several fields. Characteristics of the system such as its high controllability, energy efficiency and high ramp power rates can be exploited in wind or photovoltaic power plants. In this regard, and for instance, flywheels can be used to smooth fast output fluctuations of wind turbines, improving their output power quality and thus helping in their integration into weak or isolated power systems [4]. The performance of microgrids can be also improved by exploiting the benefits of flywheels.

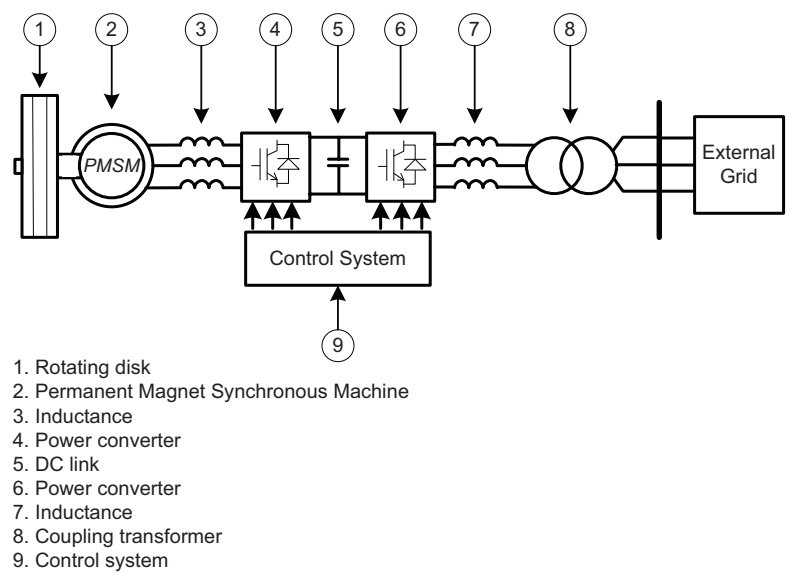

Fig. 1. System topology

This work deals with the modeling, control and experimental validation of a flywheel-based energy storage device. The system is integrated into IREC's microgrid. This lab-scale microgrid enables to study different aspects about renewable sources integration into the grid, as well as energy storage devices, communication protocols and development of control strategies for energy management of microgrids. Thus, the setup of this storage device allows the study of its applications in wind power and microgrid fields. The flywheel has been designed as a proof of concept. It is based on a rotating disk mechanically coupled to a Permanent Magnet Synchronous Machine (PMSM). It is a low-speed system type since the rotating rated speed is $3000 \mathrm{rpm}$. Electrical power is exchanged with the external grid by means of a set of a back-toback power converters (see Figure 1). These power electronics control the speed of the machine, and thus the active power absorbed or injected by the device, and also the regulation of the reactive power at the point of common coupling. 


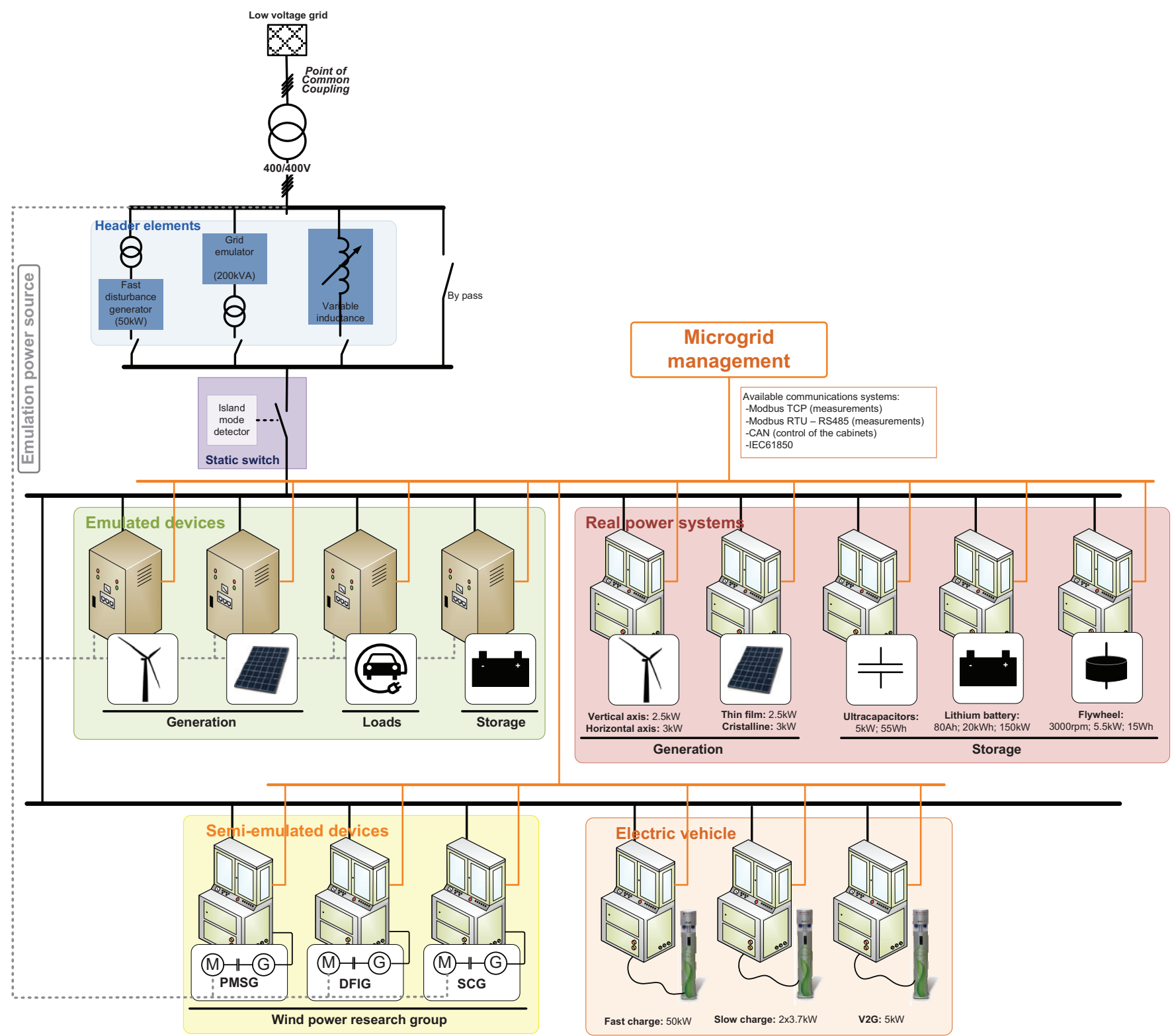

Fig. 2. IREC's microgrid

\section{IREC'S MICROGRID AND FLYWHEEL DEVICE}

The flywheel-based storage device is integrated in IREC's microgrid. As shown in Figure 2, IREC's microgrid is a flexible system that includes emulated devices, semi-emulated devices, real power systems, electric vehicle fast chargers and header elements. Emulated devices comprise several cabinets that emulate generators, loads or storage devices by adjusting the consumption or absorption time-dependent reference curves of their power electronic converters. The units are managed and controlled by energy efficient algorithms, and measurement systems provide real time supervision and regulation. Test benches that emulate wind turbine generators of different technologies comprise semi-emulated devices. These test benches emulate wind turbines driving a permanent magnet synchronous generator, a doubly feed induction generator and a squirrel cage induction generator. Each test bench comprises an electric motor driven by a frequency regulator, mechanically coupled to the shaft of the generator. This motor acts as a wind turbine, i.e., its velocity is regulated to emulate the effect of the power captured by the blades of the turbine on the shaft of the generator.

The microgrid real power systems comprise a micro wind turbine, a solar panel and storage devices as ultracapacitors, a lithium battery and a flywheel. As in emulated and semiemulated devices, controllable power electronics and measured systems are included. Finally, the microgrid includes three electric vehicle fast chargers and the so-called headers elements, which permits us to emulate different grid characteristics, faults, disturbances and so on. Rated power of the microgrid is $200 \mathrm{~kW}$. The energy management of the microgrid is carried out by communication systems with IEC 61850 standard. All these equipments permits us to study different 


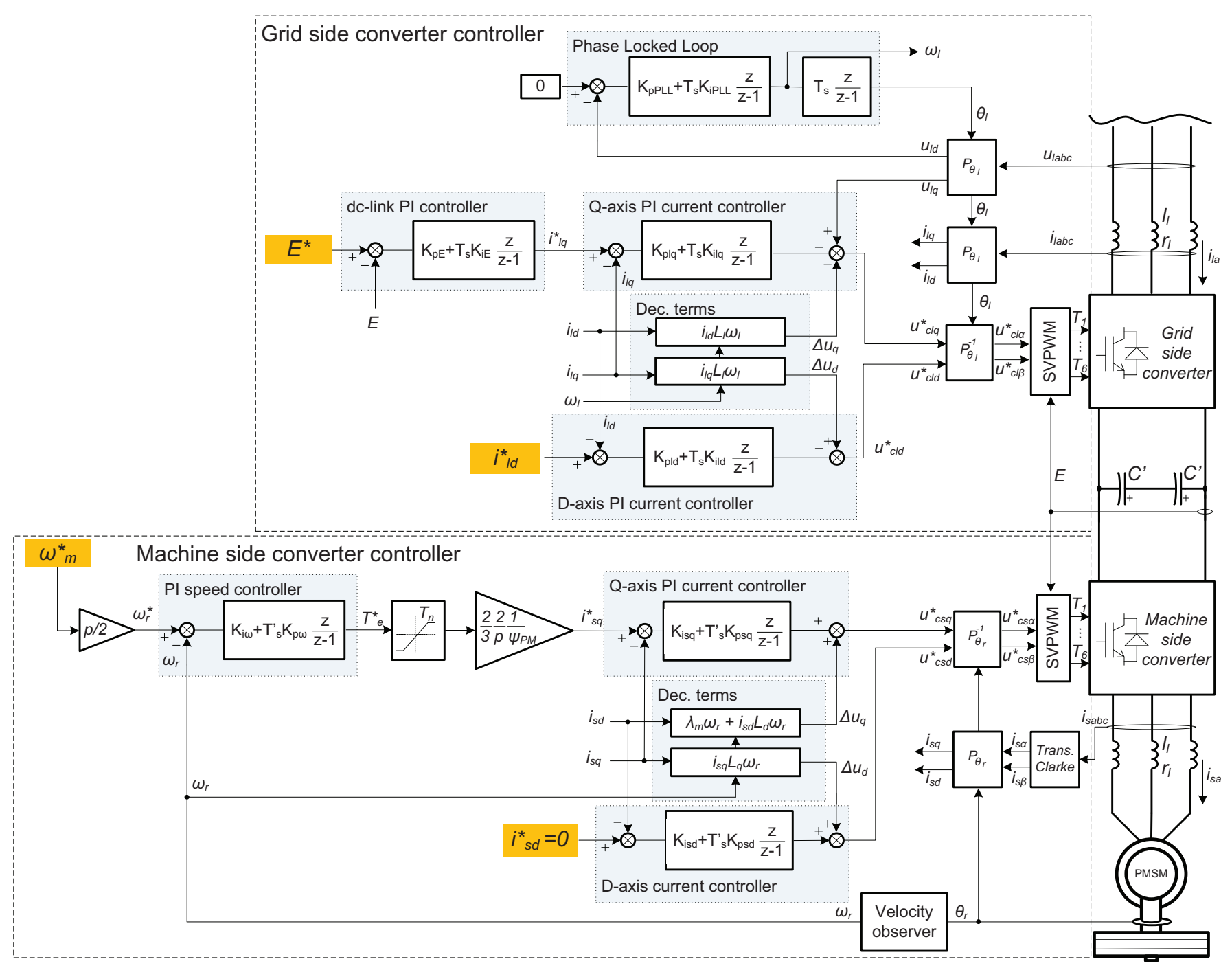

Fig. 3. Grid side and machine side vector controllers of the flywheel.

aspects related to the management, design and integration into the grid of microgrids, wind power installations and energy storage systems. More details about IREC's microgrid can be found in [5], [6], [7], [8].

\section{SYSTEM MODELING \& CONTROL}

The modeling of the storage device comprises the particular model of the PMSM as well as the power converters in a back-to-back configuration. The FESS power converters are in a back-to-back configuration. These electronic power converters are modeled as six force-commutated IGBT power switches connected in a bridge configuration. In addition, series inductances are included at the AC terminals of both the grid side converter and the rotor side converter. The modeling of the system has been carried out in Matlab Simulink.

Figure 4 shows the control system scheme. As presented, the grid side converter controller is responsible for regulating the dc-link voltage and the reactive power exchanged with the external grid. The machine side converter controller regulates the speed and the reactive currents flowing from the electrical motor.

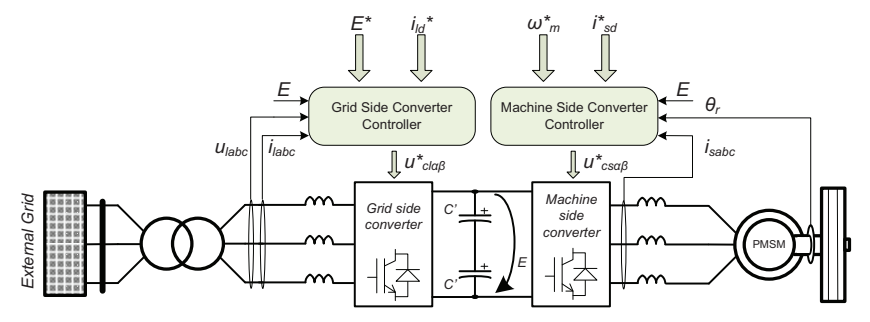

Fig. 4. Control scheme of the energy storage system

Vector control techniques are used for designing the converter controllers: a field oriented vector control algorithm [9], [10], [11] is implemented for governing the servomotor while the instantaneous power theory-based algorithm [12], [13], [14], [15] is used to manage the active and reactive currents flowing from the grid side converter.

Figure 3 details the configuration of both vector controllers. All measured voltages and currents are transformed into rotating reference frames by Park's transformation [9]. The rotating reference frame of the grid side converter controller is obtained 
from the angle of the ac voltages at the point of common coupling of the system with the external grid. The machine side converter controller uses a oriented reference frame with the rotor angle of the PMSM.

Both machine side and grid side controllers presents inner current control loops for the $d q$ currents flowing through the converters. These linear current control loops are equipped with decoupling terms in order to improve their behaviour. The outputs of them drive space vector PWM (SVPWM) schemes in order to modulate the required voltages at the outputs of the converters. The inputs of the current control loops of the grid side converter controller are obtained from an outer control loop for the dc-bus voltage $E$, and from the setpoint of the reactive current $i_{l d}^{*}$ exchanged with the external grid. Similarly, the input of the q-axis current control loop of the machine side converter controller is derived from an outer control loop for the mechanical speed of the flywheel $\omega_{m}^{*}$. The input of the $\mathrm{d}$-axis current controller is set to zero as the speed of the machine is maintained within the limit imposed by its rated value and thus no field weakening strategies are required [16].

\section{TESTING OF THE EXPERIMENTAL SETUP AND MODEL VALIDATION}

This section deals with the testing of the experimental setup and the validation of its modeling in the software Matlab Simulink. The chapter is divided in three main sections. In Section IV-A the characteristic parameters of the system are detailed. In Section IV-B the performance of the current vector control algorithm of the PM machine is introduced. Finally, in Section IV-C the dynamics of the grid side converter controller is presented.

\section{A. Description of the experimental setup}

In Table I, detailed data of the servomotor, the dc-link and the inductive filters of the system are offered. In addition, Figures 5 and 6 pictures the experimental setup. Characteristics of the PMSM and the cabinet are extracted from manufacturer's catalogues [17], [18].

TABLE I

CHARACTERISTIC PARAMETERS OF THE SERVOMOTOR

\begin{tabular}{llll}
\hline Element & Parameter & Symbol & Value \\
\hline PMSM & Rated power & $P_{n}$ & $5.5 \mathrm{~kW}$ \\
& Rated voltage & $U_{n}$ & $400 \mathrm{~V}$ \\
& Resistance (ph-ph) & $R_{s}$ & $0.44 \Omega$ \\
& Inductance on $q d$ axis & $L_{q d}$ & $2.88 \cdot 10^{-3} \mathrm{H}$ \\
& $\begin{array}{l}\text { Flux created by the } \\
\text { magnets }\end{array}$ & $\psi_{P M}$ & $0.2465 \mathrm{~Wb}$ \\
& & & \\
Rotating disk & Inertia & $J$ & $0.868 \mathrm{~kg} \cdot \mathrm{m}^{2}$ \\
Converters & Over current protec- & - & $16 \mathrm{~A}$ \\
& tion & & \\
Inductive filters & Inductance & $L_{l}$ & $4.6 \mathrm{mH}$ \\
& Resistance & $R_{l}$ & $0.3 \Omega$ \\
DC-link & Capacitance & $C$ & $0.0050 \mu \mathrm{F}$ \\
\hline
\end{tabular}

\section{B. Machine side converter controller testing and validation}

In Figure 7 the dynamics of the speed control loop is observed from a step-profiled speed reference from 0 to 15

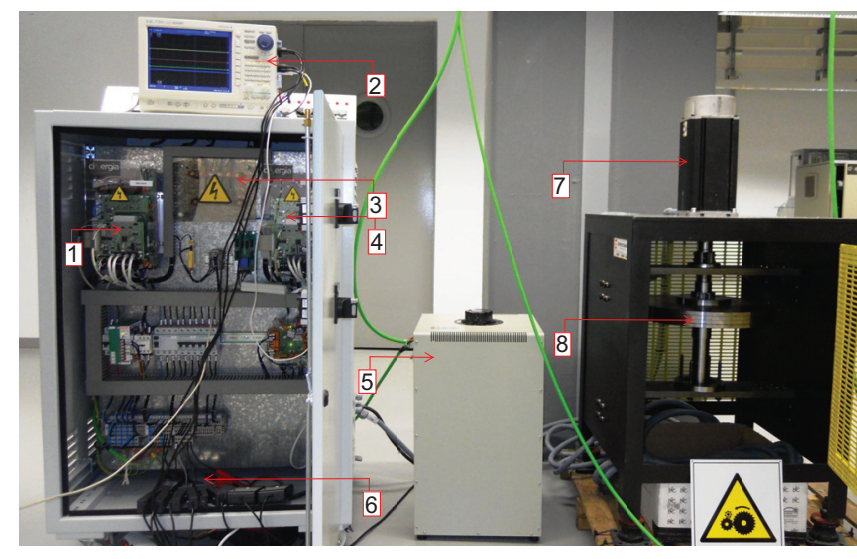

Fig. 5. Experimental setup. From left to right: item 1) Grid side converter; item 2) Oscilloscope; item 3) Dc-link; item 4) Machine side converter; item 5) Autotransformer; item 6) Measurement devices; item 7) PMSM; item 8) Rotating disk.

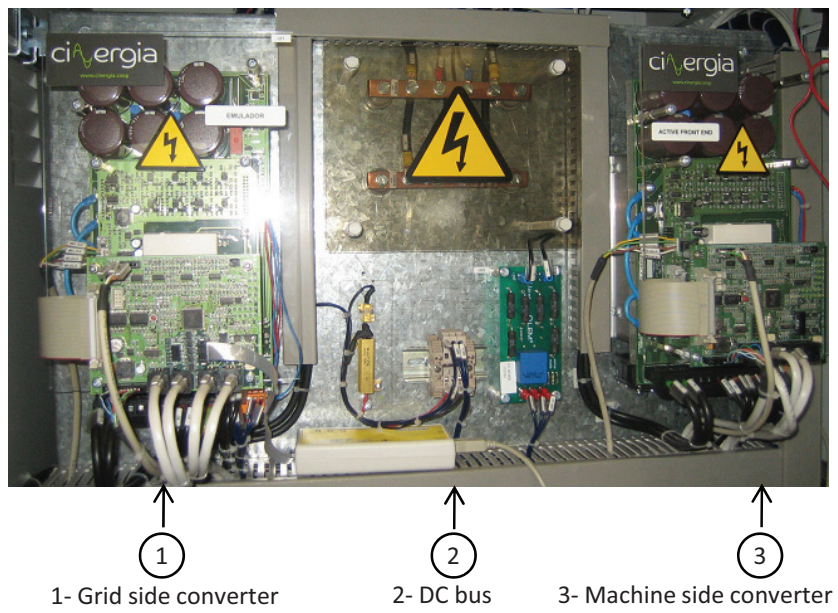

Fig. 6. Grid side, dc-link and machine side converter

$\mathrm{rad} / \mathrm{s}$. As it can be noted, the controller provides a first order system response. A steady state error can also be observed, as the integral parameter of the PI speed controller is set to zero. Finally, it can be noted the equivalence between the model and the obtained experimental results.

Figure 8 presents the stator currents of the PMSM when an acceleration of the flywheel from $50 \mathrm{rad} / \mathrm{s}$ to its rated speed and a following deceleration is performed. The stator currents have been saturated to 9 A. As shown, the system is consuming energy during the acceleration period, which lasts for 30 seconds approximately. Also, there is a permanent consumption of energy due to the losses of the system that can be clearly observed in the graph when the speed of the machine is constant. These characteristics limit the energy capacity of the storage device.

\section{Grid side converter controller testing and validation}

Figure 9 shows the dynamics of the dc-link regulator in response to a step-profiled voltage reference $E^{*}$ from $700 \mathrm{~V}$ to $750 \mathrm{~V}$. Figure 10 presents the performance of the d-axis current control loop of the grid side converter controller, i.e., 


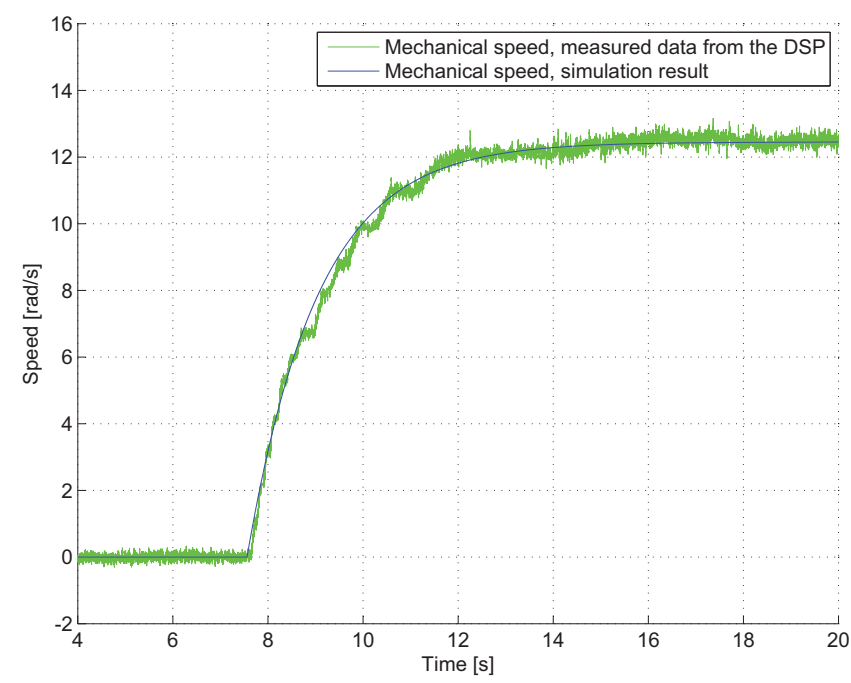

Fig. 7. Temporal response to a step-profiled speed reference from 0 to 15 $\mathrm{rad} / \mathrm{s}$.
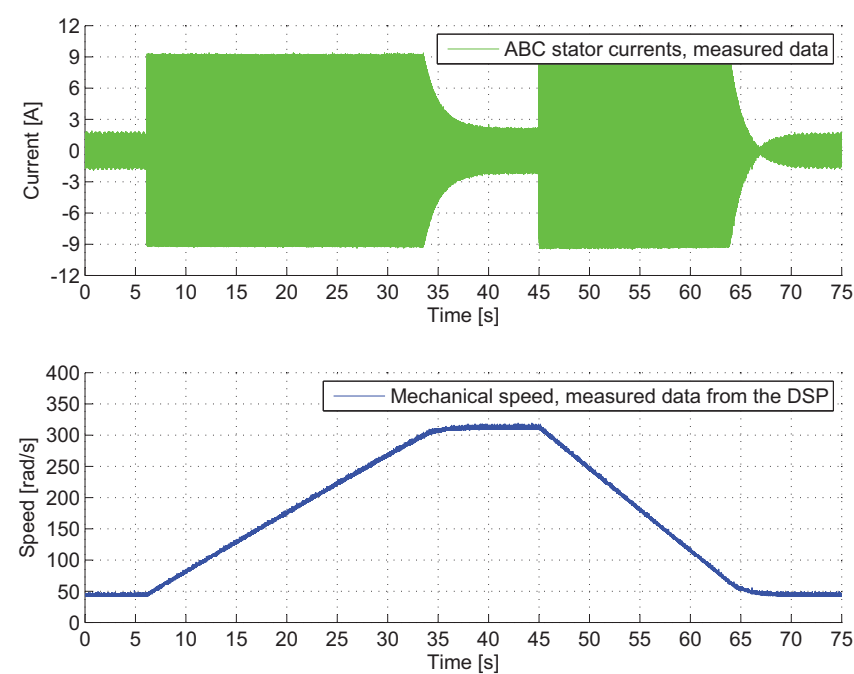

Fig. 8. Temporal response of the mechanical speed and the stator currents of the PMSM during an acceleration from $50 \mathrm{rad} / \mathrm{s}$ to $314 \mathrm{rad} / \mathrm{s}$ and a following deceleration.

the ones that regulates reactive current exchanged with the external grid. As can be noted, simulation results match with obtained experimental data.

\section{CONCLUSiOns}

In this work, the modeling, control and experimental validation of a flywheel-based energy storage device have been presented. The system comprises a rotating disk mechanically coupled to a PMSM and a set of back-to-back power converters and a two-winding transformer which allow the power transmission between the servomotor and the external grid. A field oriented vector control algorithm has been implemented for governing the servomotor while the instantaneous power theory-based algorithm has been used to manage the active and reactive currents flowing from the grid side converter. The modeling, which has been carried out in software Matlab Simulink, and control system design have been validated executing several experiments. Setting up this system opens the

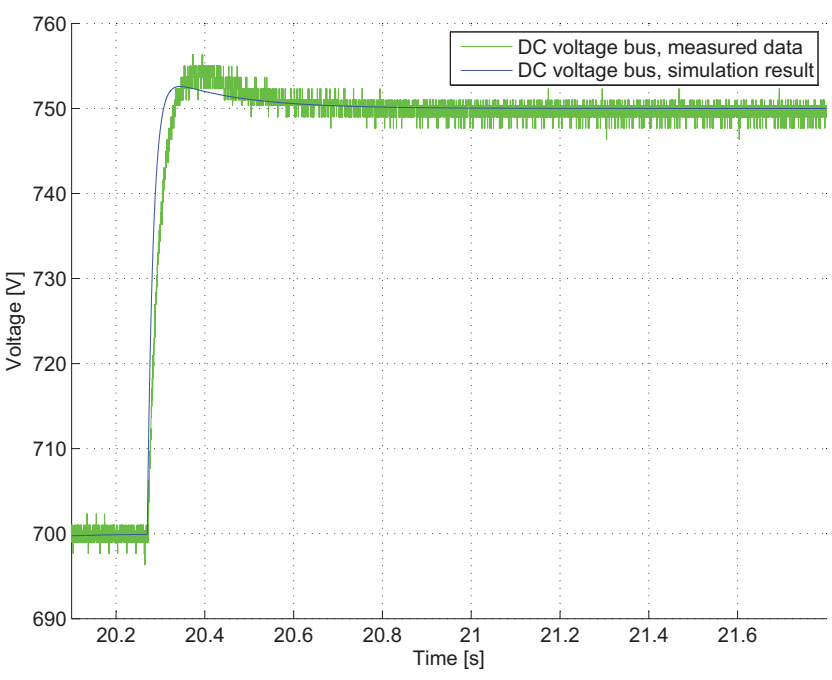

Fig. 9. Temporal response to a step-profiled voltage reference from $E^{*}$ equals to $700 \mathrm{~V}$ to $750 \mathrm{~V}$. Green line plots the measured dc-link voltage while blue line plots the simulation result.

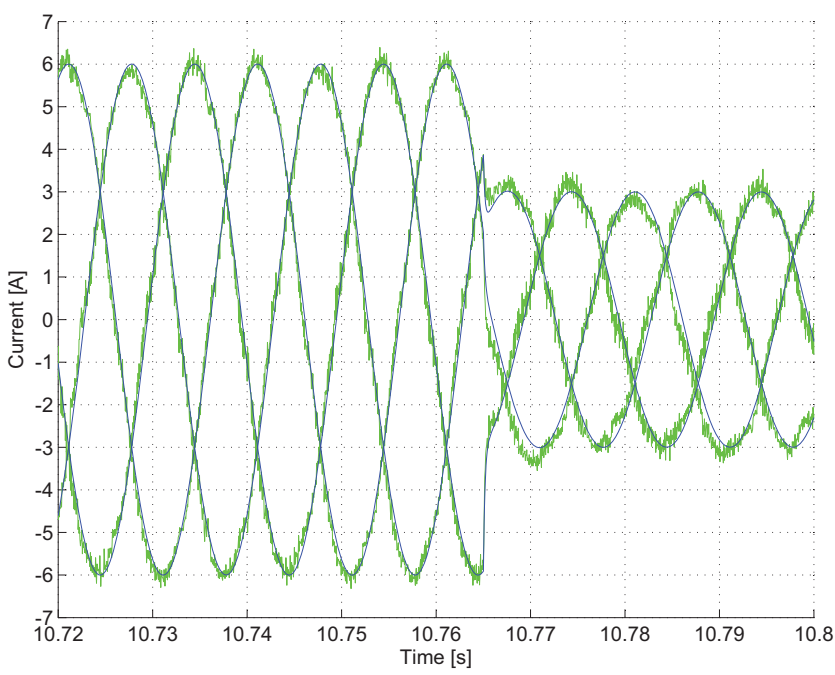

Fig. 10. Temporal response to a step-profiled d-axis current reference $i_{l d}^{*}$ from $6 \mathrm{~A}$ to $3 \mathrm{~A}$. Green lines plot measured $a b c$ currents while blue lines plot simulation results.

door to explore potential applications of flywheel systems in different fields such as microgrids and wind power generation.

\section{ACKNOWLEDGMENTS}

This work was supported by KIC InnoEnergy SE under the project Offwindtech. The research was also supported by the European Regional Development Funds (ERDF, "FEDER Programa Competitivitat de Catalunya 2007-2013").

\section{REFERENCES}

[1] B. Bolund, H. Bernhoff, and M. Leijon, "Flywheel energy and power storage systems," Renewable and Sustainable Energy Reviews, vol. 11, pp. 235-258, 2007.

[2] H. Liu, and J. Jiang, "Flywheel energy storage - an upswing technology for energy sustainability," Energy and Buildings, vol. 39, pp. 599-604, 2009.

[3] S. R. Holm, H. Polinder, and J. A. Ferreira, "Analitycal modeling of a permanent-magnet synchronous machine in a flywheel," IEEE Transactions on Magnetics, vol. 43, pp. 1955-1967, 2007. 
[4] F. Díaz-González, A. Sumper, O. Gomis-Bellmunt, and R. VillafáfilaRobles, "A review of energy storage technologies for wind power applications," Renewable and Sustainable Energy Reviews, vol. 16, pp. 2154-2171, May 2012.

[5] A. Colet-Subirachs, A. Ruiz-Álvarez, O. Gomis-Bellmunt, F. AlvarezCuevas-Figuerola, and A. Sudria-Andreu. "Centralized and distributed active and reactive power control of a utility connected microgrid using IEC61850," IEEE Systems Journal, vol. 6, pp. 58-67, 2012.

[6] A. Ruiz-Álvarez, A. Colet-Subirachs, F. Alvarez-Cuevas-Figuerola, O. Gomis Bellmunt, A. Sudria-Andreu, "Operation of a utility connected microgrid using an IEC 61850-based multi-level management system," IEEE Transactions on Smart Grid, article in press.

[7] A. Elias-Alcega, M. Roman-Barri, A. Ruiz-Álvarez, I. Cairo-Molins, A. Sumper, and O. Gomis-Bellmunt, "Implementation of a test microgrid in Barcelona," presented at the 21st International Conference and Exhibition on Electricity Distribution, Frankfurt, Germany, 2011.

[8] O. Gomis-Bellmunt, A. Sumper, A. Colet-Subirachs, A. Ruiz-Álvarez, F. Alvarez-Cuevas-Figuerola, and A. Sudria-Andreu, "A utility connected microgrid based on power emulators," in Proc. 2011 IEEE Power and Energy Society General Meeting, pp. 1-6.

[9] P. C. Krause, O. Wasynczuk, and S. D. Sudhoff, Analysis of electric machinery and drive systems, New York, Wiley, 2002.

[10] G. Terorde, Electrical drives and control techniques, Leuven, Acco, 2004.

[11] M. Arrouf, and N. Bouguechal, "Vector control of an induction motor fed by a photovoltaic generator," Applied Energy, vol. 74, pp. 159-167, 2003.

[12] H. Akagi, E. H. Watanabe, and M. Aredes, Instantaneous power theory and applications to power conditioning, New Jersey, Wiley, 2007.

[13] A. Junyent-Ferré, O. Gomis-Bellmunt, A. Sumper, M. Sala, and M Mata, "Modeling and control of the doubly fed induction generator wind turbine," Simulation Modeling Practice and Theory, vol. 18, pp. 13651381,2010

[14] J. L. Domínguez-García, O. Gomis-Bellmunt, L. Trilla-Romero, and A. Junyent-Ferré, 'Indirect vector control of a squirrel cage induction generator wind turbine," Computers \& Mathematics with Applications, article in press.

[15] O. Gomis-Bellmunt, A. Junyent-Ferré, A. Sumper, and J. BergasJane, "Permanent magnet synchronous generator offshore wind farms connected to a single power converter," in Proc. 2010 IEEE Power and Energy Society General Meeting, pp. 1-6.

[16] R. Krishnan, "Control and operation of PM synchronous motor drives in the field-weakening region," in Proc. 1993 International Conference on Industrial Electronics, Control and Instrumentation, pp. 745-750.

[17] Control Techniques website, ;http://www.controltechniques.coop/i [accessed 19.06.12]

[18] Cinergia website, ¡http://www.cinergia.coop/i [accessed 19.06.12]

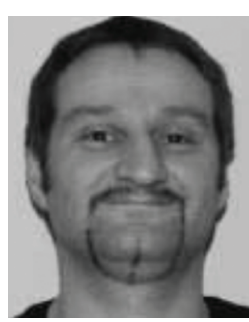

Andreas Sumper was born in Villach, Austria. He received the Dipl.-Ing. degree in electrical engineering from the Technical University of Graz, Styria, Austria, in 2000 and the Ph.D. degree from the Universitat Politècnica de Catalunya, Barcelona, Spain, in 2008. From 2001 to 2002, he was Project Manager for innovation projects in private industry. In 2002, he joined the Center for Technological Innovation in Static Converters and Drives (CITCEA) at the Universitat Politècnica de Catalunya. From 2006 to 2009, he was an Assistant Professor and since 2009 he has been a Lecturer in the Department of Electrical Engineering at the Escola Universitària d'Enginyeria Tècnica Industrial de Barcelona (EUETIB), Universitat Politècnica de Catalunya. From 2009 on, he has also been part of the Catalonia Institute for Energy Research, IREC. His research interests are power quality, electrical machines, power system studies, and distributed generation.

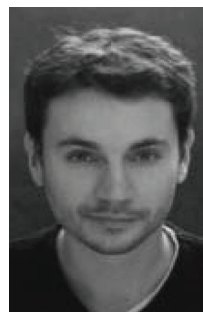

Oriol Gomis-Bellmunt received the degree in industrial engineering from the School of Industrial Engineering of Barcelona (ETSEIB), Technical University of Catalonia (UPC), in 2001 and the $\mathrm{PhD}$ in electrical engineering from the UPC in 2007. In 1999 he joined Engitrol S.L. as project engineer. In 2003 he developed part of his PhD thesis in the DLR (German Aerospace Centre) in Braunschwieg (Germany). Since 2004 he is with the Electrical Engineering Department of the UPC where he is lecturer and participates in the CITCEA-UPC research group. Since 2009 he is also with the Catalonia Institute for Energy Research (IREC), in the Electrical Engineering Area. His research interests include the fields linked with smart actuators, electrical machines, power electronics, renewable energy integration in power systems, industrial automation and engineering education.

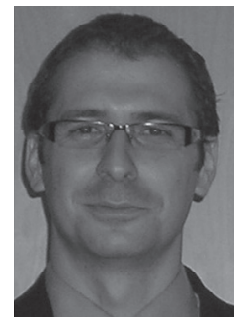

Roberto Villafáfila-Robles was born in Barcelona, Spain, and received the degree in Industrial Engineering from the School of Industrial Engineering of Barcelona (ETSEIB), Universitat Poliècnica de Catalunya (UPC), Spain, in 2005, and the $\mathrm{PhD}$ in Electrical Engineering from the UPC in 2009. Since 2003 he participates in the Centre of Technological Innovation in Static Converters and Drives (CITCEA) at UPC, where he is involved in technology transfer with the local industry due to research and innovation projects in the field of power quality, renewable energies and power systems. In 2006 he developed part of his PhD thesis at the Institute of Energy Technology, Aalborg University, Denmark. He was an Assistant Professor from 2007 to 2010, and since 2010 he is a Lecturer in the Electrical Engineering Department of UPC at the Escola Universitària d'Enginyeria Tècnica Industrial de Barcelona (EUETIB). His research interests include power systems, distributed generation, integration of renewable energy into power systems and power quality. inelds linked with energy storage technologies, electrical machines, and renewable energy integration in power systems.
Francisco Díaz González was born in Barcelona, engineering from the Schol of Industrial Engin Carcelona (ETSEIB), Technical University for Energy Research (IREC) where he is currently working on energy renewable projects in electrical engineering area. His current research interest in- 